\title{
HUAMÁN POMA Y EL ESPACIO DE LA PUREZA
}

\author{
Por \\ SARA CASTRO-KLAREN \\ Darmouth College
}

Hablar de movimientos étnicos separatistas en Latinoamérica equivale, a primera vista, a la contemplación de una ausencia. Aunque quizás de manera superfical, históricamente se podría explicar este fenómeno haciendo referencia al rápido y casi total colapso de las estructuras de las dos civilizaciones indígenas cuyo destino sería el de enfrentar los caballos europeos, las armas y las enfermedades, sin mencionar la guerra civil. ${ }^{1}$

Inmediatamente después de la Conquista, los únicos grupos que pudieron escapar a las fuerzas de integración que se desataron fueron las comunidades étnicas que ya se encontraban en la periferia de los grandes imperios, como los Yaquis de México y del suroeste americano. La resistencia de los Incas en Vilcabamba no alcanzó a durar cuarenta años (1532-1572) 2. Aún cuando habían logrado mejorar su ejército con la incorporación de caballos y de espadas, el hecho fue que cuando Manco Inca enfrentó a los españoles y a sus aliados huanca en la batalla, la derrota estaba escrita en el viento. El Imperio se había derrumbado. Los grupos étnicos que recientemente los Incas habían colocado bajo su dominio, estaban ahora en libertad 3 y los incas ahora rebeldes simplemente no podían obtener territorio suficiente que les permitiera el lujo de constituir un reino aparte. Después de la ejecución de Tupac Amaru por

1 Sobre la enfermedad como aliada formidable de los españoles, véase Alfred W. Crosby, The Columbia Exchange: Biological and Cultural Consequences of 1942. West Port, Ct.: Greenwood Press, 1972. Sobre el problema de la conquista y los ejércitos: "El ejército que capturó Tenochtlitlan era realmente un ejército de indios capitaneados por unos pocos españoles", dice Lewis Hanke (ed.), History of Latin American Civilization, Sources and Interpretations, 2 vols. (Boston: Little Brown and Company, 1973), vol. I, p. 168. Para el caso de Perú véase Waldemar Espinosa Soriano, Los Huancas, aliados de los conquistadores; tres informaciones inéditas sobre la participación indígena en la conquista del Perú, 1558-60-1561 (Huancayo: Universidad Nacional del Centro, 1971).

2 "Cuarenta años en que la penetración hispánica en Sud América tropezaba con una obstinada resistencia en Vilcabamba y el grupo seguía manteniendo la esperanza de recobrar la tierra", escribe Héctor López Martínez en Rebeliones de mestizos y otros temas quinientistas (Lima: 1972), p. 143.

3 Para mayor información sobre las divisiones étnicas que debilitaron el Imperio Inca en el tiempo de la conquista véase Waldemar Espinosa Soriano, La destrucción del imperio de los Incas: la rivalidad politica y señorial de los curacazgos andinos (Lima: Instituto Nacional de Investigación y Desarrollo de la Educación, Ediciones Retablo de Papel, 1973). 
orden del Vierrey Toledo (1572) la aristocracia inca se rindió "Y colaboró estrechamente con el interés de la metrópoli". ${ }^{4}$

Sin embargo parece que el deseo de separación étnica no desapareció ni siquiera con la llegada de organizadores tan astutos como los virreyes Toledo en Perú (1569-81) y Mendoza en México (1535-50). Aparte de las intrincadas pautas de resistencia a la integración con la cultura dominante practicadas durante las épocas colonial y republicana por el campesinado de meso y suramérica, la Guerra de Castas de Yucatán (1848) se destaca como el único hecho histórico de proporciones que podría interpretarse como una expresión de la continuidad más o menos silenciosa de un deseo de autonomía étnica. ${ }^{5}$

Podría cuestionarse la permanencia de tal deseo, pues todas las fuerzas históricas conocidas han militado, y continúan haciéndolo, contra la realización de esta aspiración. ${ }^{6}$ Estudios recientes sobre creencias populares en el Perú revelan que un mito común entre el campesinado de habla quechua del Perú sostiene que la cabeza del último Inca decapitado por los españoles en 1532 permanece viva. Está enterrada en algún lugar cercano al Cuzco, anterior centro del Imperio y del cosmos andino. El cuerpo ha estado reconstituyéndose desde entonces, y cuando esté completo y se reúna con la cabeza, el reino inca será restaurado. En ese momento los actuales dueños de la tierra serán expulsados y los indios recuperarán el dominio de su nación. ${ }^{7}$

En el fondo de este mito esquemático y explícitamente apocalíptico residen dos items de desideratum histórico: 1) la restauración de un reino nativo racialmente homogéneo y 2) la expulsión de los intrusos. El mito configura la imagen de un deseo. Su realización depende solamente del crecimiento mágico que el cuerpo del Inca pueda lograr y no requiere ninguna modificación de comportamiento por parte de los campesinos que conservan el mito. Cuando el hecho mágico sea consumado, un nuevo

4 Véase López Martínez, op. cit., p. 155.

5 En fecha tan reciente como 1848 los descendientes de los antiguos mayas, después de siglos de sumisión, se abrieron camino peleando a través de la península de Yucatán y estuvieron casi a punto de empujar a sus señores blancos al mar", escribe Nelson Reed en The Caste War of Yucatán (Palo Alto, California: University of Stanford Press, 1964), p. vii.

6 Todavía está por escribirse un estudio analítico de las numerosas rebeliones indígenas y mestizas en México, Perú, Guatemala, Bolivia y en todos los otros países donde la población podría llamarse indígena. Por tanto es imposible por el momento decir hasta qué punto estas rebeliones pueden ser interpretadas como explosiones contra una represión económica y política prolongada y en qué medida exhiben éstas un componente étnico fuerte o determinante. A juzgar por López Martínez (op. cit.) parecería que la conciencia étnica es realmente una parte importante de la identidad y de las motivaciones de los grupos rebeldes. 7 Véase José María Arguedas. Formación de una cultura nacional indoamericana, Selección y prólogo de Angel Rama (México: Siglo XX, 1975), pp. 173-182. 
tiempo nacerá. ${ }^{8}$ Pero este tiempo no es considerado como una continuación del presente. Tiene, por el contrario, la calidad distante del día del juicio final. Comparte con el tiempo de un pasado dorado la misma condición nebulosa en relación al presente y de este modo señala su neutralidad política inmediata.

Anteriormente, sin embargo, otra voz saturada por los planteos políticos de su tiempo, también imaginaba la expulsión de los españoles. Huamán Poma de Ayala, (1532?-1619) se propuso lograr el estado étnicamente homogéneo en dos pasos: el primero sería la ocupación del más nuevo de los espacios asequibles a su raza: la palabra escrita; el segundo sería el establecimiento de su nuevo "buen gobierno".

Deslumbrado por el poder político de la escritura, Huamán se procuró una nueva personae que podría soslayar la administración colonial, cruzar el océano y tener acceso directo al Rey de España (En Primer Nueva Crónica y Buen Gobierno, La Paz, 1944, folio 960-963). Su libro podría llevar a cabo lo que su persona física y legal no había logrado en ninguna corte ni ante ningún corregidor a quienes había presentado sus reclamos. Poma pensaba que después de leer su larga reflexión histórica el Rey no podría evitar el llegar a la conclusión, y ordenar, por escrito, que los indios del Perú podían y debían gobernarse por sí mismos para asegurar la sobrevivencia del Imperio Español. Huamán Poma, miembro de la clase gobernante inca por parte de su madre, había depuesto las armas que sus mayores y contemporáneos no habían podido hacer victoriosas en Vilcabamba. Concibió el proyecto de su escrito sólo unos pocos años después de la ejecución del joven Tupac Amaru I (1572), la que reprochaba amargamente a Toledo (folio 937). Tanto la separación por la fuerza como la guerra de guerrilla prolongada habían resultado ineficaces y había llegado el momento de enfrentar a los invasores dentro del espacio que ellos mismos habían inaugurado recientemente y dentro del conjunto de reglas que proclamaban haber organizado y justificaban su cosmos y, en consecuencia, la reciente conquista del Imperio Inca. Todo esto significaba que, al escribir, tendría que aceptar la existencia de un nuevo orden.

Visto retrospectivamente, el proyecto de Huamán Poma parece ingenuo $o$, en el mejor de los casos, paradójico. No obstante, un examen de la diestra manipulación de datos y argumentos contenidos en La Primer Nueva Crónica y Buen Gobierno ${ }^{9}$ demostrará que las herramientas

8 Véase en Nathan Wachtel, Sociedad e ideología, ensayos de historia y antropología andinas (Lima: Instituto de Estudios Peruanos, 1973). pp. 190-11, una discusión sobre la organización temporal cósmica clásica andina en cuatro épocas escatológicas.

9 Del relato contenido en el manuscrito podría deducirse que Poma lo escribió entre 1583 y 1613. Wachtel sostiene que Poma comenzó a copiar su crónica en 1612 y la terminó hacia 1615. (Op. cit., p. 168). 
intelectuales y los objetivos políticos de Poma fueron elegidos con gran cuidado e inteligencia. Su crónica no es en absoluto el producto mutilado de una mente primitiva que rechaza la iluminación del Renacimiento europeo, como algunos de sus primeros lectores escribieron con delectación. ${ }^{10} \mathrm{La}$ validez histórica de su proyecto era demostrada por el coro de voces españolas que aconsejaban la separación de indios y españoles, pero no gobiernos separados. El establecimiento de reinos milenarios franciscanos y de estados utópicos jesuitas ya constituye la actualización parcial de su sueño. ${ }^{11}$ En su manuscrito, silencioso durante más de trescientos años, Poma establece las bases para el mantenimiento de la integridad étnica aun a riesgo de favorecer el separatismo. "Dios permita que no nos acabemos" (folio 981). La constitución histórica de esta ideología es lo que trataré de discutir en este trabajo.

Lo que nosotros sabemos sobre Huamán Poma, el águila-león, (folio 1107) se limita a lo que él mismo había decidido decir al Rey sobre su persona en Primer Nueva Crónica y Buen Gobierno. ${ }^{12}$ Por línea paterna era descendiente de los Yarovilcas, señores de la parte Norte del Imperio. Su madre era una de las hijas de Tupac Inca Yupanqui (folio 15, también 1020-22), el penúltimo Inca. Nacido después de la muerte de Atahualpa en 1532, declara haber pasado la mayor parte de sus ochenta y siete años tratando de combatir los abusos de los españoles ("mira cristiano, a mí todo se me ha hecho" [folio 916]) en su aldea, de la cual fue finalmente expulsado por un corregidor codicioso. En sus últimos treinta años su empresa literaria absorbió todas sus energías. Pasó mucho de su tiempo recorriendo el territorio, explorando la memoria de los ancianos y observando el brutal comportamiento de los españoles, minuciosamente y con la muda indignación de un inquisidor. Su reflexión-una labor dolorosa, pues nos dice que escribir es llorar (folio 1111) se convirtió finalmente en un enorme manuscrito ilustrado (más de mil páginas y quinientas ilustraciones). No se sabe casi nada sobre el momento y el lugar en que llegó a adquirir tanta información sobre las nuevas categorías de

10 Véase, por ejemplo, "Juicio crítico de R. Pietschman" en el apéndice al libro de Julio C. Tello, Las primeras edades de Perú por Huamán Poma de Ayala (Lima: Ed. Lumen, 1948), p. 7.

$11 \mathrm{La}$ existencia entre los misioneros franciscanos de México de un reino milenario heredado de Joachim de Floris por intermedio de San Francisco de Asís se discute extensamente en Jacques Lafaye, Quetzalcoatle and Guadalupe, the Formation of Mexican Consciousness, 1531-1813 (University of Chicago Press, 1976), pp. 30-31. Lafaye discute también (p. 33) el experimento utópico de Fray Vasco de Quiroga en Michoacán con los indios tarascos. Para mayores detalles sobre el experimento franciscano véase John L. Phelan, The Millenial Kingdom of the Franciscan in the New World (Berkeley: University of California Press, 1958). 12 R. Pietschman encontró el manuscrito en la Biblioteca Real de Copenhagen en 1908. Yo he usado la edición impresa transcripta y anotada por Arthur Posnansky, publicada en La Paz en 1944. Todas las referencias a los folios se hacen por esta transcripción. 
pensamiento europeas (folios 912, 918, 1069-70) ${ }^{13}$ y la controversia española sobre los derechos humanos de los indios en relación a su situación en el Imperio. Profesando no saber latín ni tener el beneficio de ningún título ni escolaridad alguna ("no soy letrado" [folio 8]) se disculpa por los errores que pueda cometer al escribir. Proveniente de la cultura vencida y de una tradición nativa puramente oral, encara la escritura, categoría totalmente nueva de pensamiento, con vacilación. ${ }^{14}$ La Primer Nueva Crónica, al igual que la Biblia (folio 912, 1065), tal vez el modelo más cercano que Huamán tenía en su mente, trata de muchas cosas y puede ser útil en diversos aspectos. Contiene datos inapreciables sobre las civilizaciones pre-inca e inca ${ }^{15}$, así como detalladas descripciones de la drástica disminución de la población india en el S. XVI ${ }^{16}$ (folio 1102/951). Puede también considerarse como una metáfora del encuentro de dos mundos dentro de una mente individual: vaivén dialéctico comparable al movimiento radical de las mareas en las plataformas continentales.

La larga defensa de la pureza étnica y del separatismo, que en la mayor parte del manuscrito permanece tangencial $y$ entretejida con otros

13 Wachtel ha demostrado que, aunque aparentemente confusas, sus secuencias del flujo del tiempo desde la creación del mundo hasta el presente obedecen a categorías andinas de espacio y tiempo. En efecto, Poma logra insertar el tiempo y el espacio cristiano en las divisiones cuatripartitas de tiempo y espacio andinas (pacha), (op. cit., pp. 202-226). Y todavía hay otra corriente contraria en su pensamiento, que insertará el tiempo indígena y el cosmos indio en la cultura imperial europea en expansión. En "Las otras fuentes de Huamán Poma: sus lecturas castellanas", (Histórica, Lima, Vol. II, Dic., 1978) Rolena Adorno demuestra que Poma conocía muy bien no sólo las ideas de Las Casas, sino también las del Obispo Loaya, “Avisos para confesores",. el Léxico de Domingo de Santo Tomás, el Tratado de doce dudas así como El tercero catecismo y exposición de la doctrina cristiana por sermones, primer libro impreso en América.

14 Parecería, por sus constantes comentarios laudatorios sobre su medio hermano el hermitaño Martín de Ayala, que era éste quien lo instruía en las cuestiones de la fe católica. Los misioneros predicadores son probablemente otra de sus principales fuentes. Mientras recorría las ciudades españolas y las villas indígenas seguramente oyó muchas misas y sermones. Como ocurre hoy día con los que no saben leer y escribir que se enteran a diario de los problemas de su tiempo a través de la televisión o de la radio, Poma parece estar totalmente atrapado por la mera fascinación de la palabra y en el recuerdo puede sin embargo enfurecerse ante la incomprensión de su cultura que se tradujo en evangelización y extirpación de la idolatría.

15 La reconstrucción del sistema de los ceques del Cuzco por R. T. Zuidema en The Ceque System of Cuzco: The Social Organization of the Capital of the Inca (Leyden, E.J. Rill, 1964) y la revisión de Wachtel de la tesis de Zuidema, (op. cit. pp. 230-258) hacen un extenso y brillante uso de los datos disponsibles en el manuscrito de Poma.

16 En la historiografía del Perú no hay equivalente a Charles Gibson, The Aztecs under Spanish Rule: A History of the Indians of the Valley of Mexico, 1519-1580 (Palo Alto, California: Stanford University Press, 1964), pero su afirmación "la sociedad india parecía encaminarse a la extinción a fines del S. XVI" está expresada con demasiado énfasis en las páginas de Nueva Crónica, donde Huamán Poma nos dice que "A donde había en la visita general cien indios tributarios no hay diez" (folio 931) (Lewis Hanke, op. cit., p. 155). 
innumerables tópicos, ha sido a menudo descripta como el bosquejo de una utopía.

Al tratar de establecer las diferencias entre ideología y utopía Mannheim dice que

every period in history contained ideas transcending the existing order, but these did not function as utopias, they were rather the appropriate ideologies of this stage of existence as long as they were "organically" and harmoniously integrated into the world view characteristic of the period. . . Not until certain groups embodied these wish images into their actual conduct, and tried to realize them, did these ideologies become utopias. 17

Teniendo esto en cuenta y anticipándonos a los argumentos a favor del "buen gobierno", parecería que el manuscrito de Poma constituye un conjunto de proposiciones ideológicas no tan "armoniosamente" integradas en la "visión mundial característica del período" (europeo), aun cuando fueron explicitadas con el propósito de proclamar las razones que justificaban la dominación de los habitantes recientemente descubiertos del Nuevo Mundo. Las ideologías existentes (tanto andinas como europeas) no habían anticipado la realidad y en el tiempo en que Poma vivió se modificaron hasta convertirse en formas contorsionadas que les permitieron absorber el choque con la realidad. Además, si consideramos que la ideología europea era la visión del mundo característica del grupo dominante y tenemos un miembro del grupo vencido tratando de convertir en comportamiento real la ideología del grupo dominante, encontramos que la definición diferenciadora de Mannheim no nos es de mayor utilidad. Para pensar en los términos de Mannheim tendríamos que dar por sentado que la ideología de los colonizadores y de los conquistadores del siglo XVI era uniforme, cuando sabemos que en realidad la Corona, las órdenes misioneras y los colonizadores frecuentemente disentían en cuanto a la comprensión de los fines y significado del comportamiento español en el Nuevo Mundo. Para complicar las cosas aún más, no sabemos hasta qué punto el resto del grupo de Huamán Poma, que tampoco era monolítico, estaba preparado, ideológica o prácticamente, para convertir en comportamiento la imagen/deseo de un estado étnico autónomo. Por tanto debemos considerar las peticiones ideológicas de Poma y su proyecto para el futuro fuera de categorías restrictivas tales como praxis de la ideología durmiente y praxis ideológicamente activada de la utopía.

Al evaluar el impacto del Nuevo Mundo sobre el antiguo, parece ahora cierto que la crítica de Thomas More contra el individualismo económico sin restricciones y su inclinación por los derechos de propiedad comunal

17 Karl Mannheim, Ideology and Utopia (New York, 1936), pp. 173-174. 
estaba inspirada en lo que había leído sobre las sociedades indígenas en las cartas de Vespucio. ${ }^{18}$

Probablemente el hecho de que el proyecto de Huamán Poma para el futuro comparte esta característica con la sociedad insular que More propone es la causa de que haya sido calificado de utópico. Sin embargo hay diferencias muy significativas entre los sueños de estos dos contemporáneos: Huamán Poma usa su propio pasado histórico, una experiencia concreta, como modelo para un futuro inmediato. Los ensueños de More, aunque fundamentados en una crítica del presente, están parcialmente inspirados en un fragmento de un orden humano distante e imperfectamente conocido. Como el modelo de Huamán Poma se apoya en una parte de su propia existencia, su proyecto no requiere ni tiempo ni espacio remoto, no persigue un experimento dudoso: su estado autónomo puede ocurrir en su tiempo y en su espacio. Bastará solamente cortar todo vínculo con el mundo español; mantener el nuevo espacio herméticamente cerrado al mundo exterior y comenzar la tarea de restauración - no de experimentación-y nuevo crecimiento. ${ }^{19} \mathrm{La}$ invasión española podría ser absorbida por la sociedad andina como una especie de poda casi catastrófica, pero de la cual el tronco del árbol podía todavía reponerse. El discurso de Poma es una empresa de fundación dentro de la conciencia de fractura que la invasión de América inaugura.

La oposición funcional en la mente de Poma, típica oposición renacentista pero también muy concreta según su experiencia, es la de las ciudades españolas y las comunidades indígenas. Para Poma la tarea a su alcance era aceptar la conquista y minimizar las pérdidas, dejar las villas y las ciudades a los españoles con su población de esclavos negros y mestizos, y devolver los indios a sus caseríos y a sus campos, donde podrían reagruparse de acuerdo a las divisiones étnicas pre-incaicas. ${ }^{20}$

Al igual que la mayoría de los escritores indios o mestizos de su época, Huamán Poma había sufrido una pérdida total de poder y de posición

18 Véase Arthur J. Slavin, "The American Principle from More to Locke", en Fredi Chiappelli (ed.), First Images of America, 2 vols. (Los Angeles: University of California Press, 1976), vol. I, pp. 142-147.

19 Poma razona con el Rey "que es muy justo y servicio de Dios y su magestad de que los españoles no se puede poblar junto con los Indios en las ciudades ni en las villas, aldeas, ni vaya a morar ningún español ni española ni mestizo ni zambahijo ni cholo . . que los Indios se hacen bellacos y borrachos, jugadores perezosos, ladrones, cimarrones. Viviendo con ellos se alzarán y se harán traidores" (folio 543).

20 En este respecto Poma va mucho más lejos que la cédula de 1578 de Felipe II que prohibía a los negros, mulatos y mestizos, pero no a los españoles, estar en compañía de los indígenas, con el objeto de prevenir la corrupción de los "naturales". Aunque la ley establecía una severa segregación, ésta nunca fue realmente obedecida y Poma tiene conciencia tanto de la existencia de la ley como de su aplicación ineficaz. Véase Charles Gibson (ed.), The Spanish Tradition in America (New York: Harper and Row, 1968), pp. 135-36. 
social (folio 1105-1106). ${ }^{21}$ Escribe, en este sentido, desde los márgenes del poder establecido, aunque no se pronuncia contra la autoridad ni contra las formas de represión que la civilización trae consigo, como lo hace Charles Fourier a fines del siglo XVIII en Francia.22 $\mathrm{Si}$ estos dos soñadores ${ }^{23} \mathrm{de}$ un nuevo orden se encontrasen hallarían muy poco terreno común. La sensibilidad moral de Huamán Poma no tiene límites; su capacidad de indignación moral es inagotable y cuenta con que el lector "cristiano" estará de su parte. ¡Condenado sea el lector que no esté dispuesto a enjuiciar un flagelamiento, una violación, una decapitación, o un despojo! La desesperación por la pérdida sufrida y la urgencia por restaurar el mundo antes de que sea demasiado tarde, obsesionan su mente. Fourier y su falange de buscadores de placer probablemente merecerían ser arrojados al mar junto con el corregidor avaro, el juez voraz y el sacerdote sensual. A ojos de Poma estas gentes habían venido a América para corromper un orden justo e incontaminado. Han puesto "el mundo al revés" y de alguna manera están produciendo el infierno cristiano donde "habrá hambre, y sed y llanto y crugir de dientes y gusanos y escorpiones" (folio 944). Para el moralista Poma, el culto de los sentidos, preferencias y emociones del individuo solamente conduce a una nerversión mayor.

Antes de proseguir con la descripción de la organización del estado indígena bajo el gobierno español, creo que es necesario examinar la base ideológica de la táctica de Huamán Poma, pues ella determina los parámetros de la imaginación de este soñador.

Un sentido de dualidad impregna todos los aspectos fundamentales del texto. El autor es por lo menos bilingüe. El manuscrito está dirigido a los "lectores" que pueden leer caracteres abstractos y, con sus ilustraciones, al público iletrado capaz de leer las imágenes. Abarca una reflexión histórica y un proyecto para el futuro. Su discurso supone, además, otros dos tipos de lectores: el lector cristiano del manuscrito publicado (folio 7) y el lector Cristiano del texto sin publicar.

En general la primera parte del texto está dirigida a Felipe II (d. 1598) y la segunda presupone a Felipe 111 como lector. Por impensable que pueda

21 "sean mestizos o indios . . un hecho innegable surge de la historia de sus vidas: su fracaso social . . . Cada uno en su órbita, fue arrojado de la posición a la que habría podido pretender por su nacimiento", escribe Nicole Girón de Villaseñor en Perú: Cronistas indios y mestizos en el siglo XVI (Mexico: SepSetentas, 1975), p. 98.

22 Charles Fourier, Design forUtopia, Selected Writings of Charles Fourier (New York: Schocken Books, 1971).

23 Estoy usando el término sueño en el sentido que Gaston Bachelard le ha dado en The Poetics of Space, translated by Etienne Gibson. 
parecernos, no cabe duda de que Poma realmente esperaba que el Rey sería su primer lector, gobernaría según sus propuestas y ordenaría la publicación de su trabajo. Investido de su nueva personae como autor, el creciente orgullo de Poma le permite imaginar una escena en la cual mantiene un diálogo con el Rey (folios 960-973). Cualquiera de los dos Felipes le pediría, como podrían hacerlo a sus consejeros de confianza, tales como el Duque de Alba con el que se compara, su consejo sobre como poner fin a los brutales estragos que los burócratas españoles producían y a la consiguiente despoblación del Peru. ¿En qué basaba Huamán Poma sus pretensiones ¿Cómo podría un hombre vencido como él persuadir al Rey de que estableciera un reino aparte de y para indios exclusivamente, cuando ya el Nuevo Mundo estaba lleno de mestizos, mulatos, negros, zambos y blancos? La respuesta es muy compleja, pero por lo menos en parte se vincula a que Huaman Poma suponía, acertada o equivocadamente, que la lucha ideológica era la determinante más importante de su tiempo.

Otra motivación de Huamán Poma parece haber sido la confianza en el poder de la palabra como metáfora del mundo (folio 912). Aunque en su argumentación no utiliza una lógica lineal y explícita y aunque prefiere la acumulación de datos, lo que finalmente construye es una vasta red de alusiones. El poder de resonancia de su material descriptivo así como sus muchos apartados adquieren total significado si no olvidamos que el contexto de su escritura es el problema político teológico que surgió en Europa con el descubrimiento de los indios. Este autor indio no sólo estaba bien al tanto de que para resolver problemas políticos tenía que comprometerse con el discurso religioso, sino que reconocía que no había distinción alguna entre ellos. Consideraba de primordial importancia la razón que se aducía para justificar la guerra contra los indios y la conquista misma: la evangelización. De modo que trató de utilizar-no sabemos si con ingenua sinceridad o con gran astucia-las mismas armas que habían declarado a él y a su vencida raza niños irresponsables. ${ }^{24}$ Apuntando las armas en dirección contraria, él podría demostrar que los españoles eran realmente malos cristianos; inmorales, despiadados, codiciosos, etc., y por tanto no tenían derecho a gobernar la tierra, y mucho menos a los indios. ${ }^{25} \mathrm{Al}$ cuestionar la legitimidad de la conquista

24 Una comparación con los llamamientos ideológicos del movimiento negro en los Estados Unidos, especialmente el de Martin Luther King, proporcionaría muchas similitudes y diferencias iluminadoras, pero no serán consideradas en este trabajo por limitaciones de espacio.

25 Girón de Villaseñor señala que la "obra civilizadora de los españoles es menos brillante que la de los Incas para el Inca Garcilaso y también menos brillante que la de los Yarovilcas para Huamán Poma" (op. cit., p. 131) 
española, su trabajo se convirtió en subversivo, junto con las obras de muchos españoles que también la habían cuestionado. Es decir, que un salvaje idólatra también podía ser considerado sacrílego.

A lo largo de su repetitiva y tediosa descripción de los abusos españoles - sadismo parecería muchas veces la palabra adecuada-está diciéndole al mismo Rey que su gobierno es inepto. Le informa que no ha cumplido su parte correspondiente del pacto con los pueblos indios: tierras a cambio de almas. Informa a Felipe II/III que no está enviando sacerdotes y encomenderos a sus nuevos súbditos de América. Lo que había hecho, en cambio, era soltar un montón de "ratas, gatos, leones y víboras" (folio 704) sobre la carne inocente de una fiel y excelente fuerza de trabajo. La comparación de los españoles con una fauna carnívora acarrea un impacto más político que literario. Su animalización pone énfasis en el comportamiento "salvaje" de los señores, y de esta manera Poma cuestiona directamente la base "espiritual" que justificaba la ideología de explotación y dominio que estaba viviendo.

A ojos de Poma los indios, pura carne "natural", son capaces de dos de los más altos valores humanos: trabajo y organización social. Los españoles, por el contrario, viven del trabajo de otros y no pueden siquiera organizar el gobierno del Imperio.

Poma ha señalado aquí un punto de gran importancia ideológica. Sabe, además, gracias a la simple observación de los españoles con los que entra en contacto, que la parte ética de su ideología no es el factor principal que motiva su comportamiento: de otra manera no se explicaría que las mujeres fueran azotadas porque les faltara un huevo en su tributo. En consecuencia, Poma se dirige al bolsillo del Rey, advirtiéndole las consecuencias desastrosas que ocasionaría a la economía del Imperio la despoblación nativa (fuerza de trabajo) hasta el punto de su extinción (1102). El rey seguramente escucharía a los que se encontraban en posición que les permitiera predecir el destino de su alma y de su oro, pero escucharía especialmente a los que fueran capaces de impedir el desastre y de garantizar un flujo continuo de oro.

Si la imitación es el más alto homenaje que una persona, grupo o clase puede rendir a otro, Poma, al emular a sus mejores, pero quizás más astutamente al apaciguar la Inquisición, hace del arrepentimiento ("reforma") de las almas el propósito visible de su escrito. La intención moral de su crítica amortiguará la peligrosa violencia política de sus ejemplos y lamentaciones.

Irónicamente es en esta coyuntura de su obra que el proyecto futuro comienza a convertirse en historia. Aparte del cristianismo, la lectura y la escritura son las únicas herencias culturales que está dispuesto a retener 
(folio 792). Todo lo demás, exceptuando tal vez las tijeras, debe ser devuelto al lugar de procedencia. Para Poma el mejor orden de cosas ocurre cuando las cosas y la gente permanecen donde Dios las colocó originalmente. "Dios hizo la tierra y plantó en ella cada simiente. El español en Castilla, el Indio en las Indias, el Negro en Guinea... que otro español no tiene por qué entrar, porque el Inca era propietario y legítimo rey y así Castilla es de los españoles y las Indias de los Indios y Guinea de los Negros" (folio 566-591).

Por sádica y destructora que, como se había demostrado, fuera la dominación española, no había posibilidades de pensar en otra salida que la reforma. Con la circulación de la Breve Historia de la Destrucción de las Indias (1542) Las Casas había convencido ya a muchos de sus contemporáneos de la incapacidad moral de los españoles para gobernar las colonias. Los dominicos habían incluso sugerido la temeraria idea de que los mestizos eran los que estaban capacitados para gobernar. Sus padres habían conquistado la tierra y sus madres la habían heredado. La respuesta de la Corona fue la emisión de más leyes (folio 542) protegiendo a los Indios y más leyes conteniendo a los mestizos, inquietos, ambiciosos y rebeldes.

En vista de esa posición mental ¿qué otra cosa podía argüirse para defender el derecho de los indios a gobernarse? Poma debía convencer a su Lector Cristiano, su señor, de que el Indio es un ser humano capaz. ${ }^{26}$ Argumenta con eficacia que su compañero indígena no es un ser humano solamente en virtud del razonamiento teológico, sino en virtud de la historia de su nación (o grupo étnico) que le garantiza por lo menos igual capacidad de administrar la tierra y de gobernar a la gente. ¿Era esto escandaloso, considerando el etnocentrismo europeo? Sí. ¿Imposible? Huamán Poma no lo consideró así en el momento en que se decidió a escribir. ${ }^{27}$

En consecuencia Huamán Poma comienza su extendido argumento igualador con un asalto al Tiempo. Totalmente consciente de que la composición narrativa de la Biblia es el mecanismo por el cual los españoles calculaban el tiempo y la legitimación política de los hechos históricos, Poma trata de encontrar los puntos débiles que le permitan

26 Aunque Hayden demuestra que la función del tema del salvaje noble en el S. XVIII es fetichista, no sería anacrónico extender su análisis a las leyes de la Corona destinadas a proteger a los llamados "naturales". Véase Hayden White, "The Noble Savage: Theme as Fetish", (en Slavin, op. cit., pp. 121-135).

27 Aquí difiero de la opinión de Wachtel y creo que el propósito político de Poma es más bien ubicar al indio en el cosmos europeo que invertir la operación, aunque, como Wachtel demuestra con su análisis del "mapa mundi" de Poma, sus categorías geográficas le permiten integrar al Rey de España y al Papa en el Cosmos Andino de los cuatro rincones, de lo alto y de lo bajo. 
introducir el Tiempo Indio en el flujo lineal del Tiempo Cristiano. Su necesidad apremiante es demostrar que los Indios, pero especialmente su grupo étnico, los Yarovilcas, eran descendientes de Adán y Eva (folio 80) ${ }^{28}$ El Diluvio les parece, como les había parecido a muchos teólogos y misioneros españoles, ${ }^{29}$ un acontecimiento plagado de suficiente confusión sobre quienes y cuantos habían sido salvados como para permitir la teoría de una tercera creación en la cual algunos de los descendientes de Noé fueron traídos por Dios mismo para poblar el Nuevo Mundo. Aquí Poma sigue los lineamientos del pensamiento de su época (tanto europeo como indio) respecto a la idea de una sola creación como única posible. Esta noción ha continuado dominando el pensamiento europeo, aun en sus expresiones más modernas y científicas, como, por ejemplo, la teoría de la evolución y de la migración de los "indios" a este hemisferio por el estrecho de Bering.

Más preocupado con la mecánica concreta de reproducción que la Biblia misma, Huamán Poma hace toda clase de especulaciones sobre la rapidez con que la tierra podría haber sido poblada. Su preocupación por el crecimiento y disminución de la población, como veremos luego, no es un mero juego intelectual. Anteriormente algunos comentadores han insinuado que Poma es una muestra de la peculiar fascinación por los números típica de la preocupación estadística de los Incas. Esto bien podría ser verdad, pero no puede olvidarse que lo que él quiere es un Estado Indio con el expreso propósito de promover la reproducción de los indios (folio 481 ), cuyo descenso de población se había convertido en una frase obsesiva ("se despueblan las Indias") en las mentes de sus contemporáneos, tanto indios como españoles.

En el momento en que escribe, el crecimiento de la población era literalmente un juego de vida o muerte para su raza. Tanto aquí como en otras manifestaciones de su discurso, encontramos que lo concreto está íntimamente ligado a la ideología política y ésta a su vez se vuelve inseparable de las consideraciones religiosas o cosmológicas.

Poma es bien consciente de que el problema de la descendencia de la pareja original es básico para la consideración del gran tabú del incesto. Los españoles habían usado la costumbre inca de casarse con sus hermanas para declararlos inmorales e ineptos para gobernar y por lo tanto merecedores del yugo español. Recurriendo otra vez a la confusión, ve la salida de la zona de peligro. Propone que, como Adán y Eva, los fundadores de la tercera edad en el Nuevo Mundo seguramente han tenido

28 Por supuesto no es original en este punto. Pero no es su originalidad lo que me interesa, ya que lo que estoy tratando de demostrar es su habilidad para adaptar el complejo pensamiento europeo renacentista a sus necesidades políticas, étnicas y personales.

29 Véase Lafaye, op. cit., pp. 30-50. 
vidas muy largas y han sido padres de muchas parejas de mellizos. En muy poco tiempo debía haber habido tanta gente en edad de procrear que se había hecho imposible controlar las relaciones de cada individuo. Y aún más, cuando páginas después habla del origen divino del Inca-Hijos del Sol-implacablemente destruye tales pretensiones al echarles en cara la acusación de incesto. Para Poma, los orígenes divinos del Inca son solamente un fraude, $y$, por añadidura, Manco Capac era el producto de la creación sin padre de una ambiciosa madre/bruja que se casó con su hijo y después inventó la historia de la ascendencia divina directa (folio 81).

$\mathrm{Si}$ la acusación de incesto contra sus antepasados Yarovilcas es rechazada de una manera por lo menos tan confusa como la de la Biblia, la cuestión de los derechos humanos como corolario exclusivo del Cristianismo, en cambio, no lo es. El "descubrimiento" del Nuevo Mundo había puesto en crisis la mayoría de las nociones europeas de la naturaleza humana (ni divina ni animal) ${ }^{30}$ Las teorías contemporáneas sobre el derecho de hacer la guerra y de apoderarse del botín de la conquista, así como los derechos económicos, políticos y sociales de los individuos súbditos del estado, tendrían que examinarse nuevamente a la luz de una nueva presencia: el indio. La mente de Huamán Poma parece sumergirse en el debate que siguió a la publicación de la Destrucción de Indias de Las Casas, especialmente entre Sepúlveda y Victoria. Seguramente tuvo acceso a los argumentos de ambas partes. Por supuesto vio y consignó en su obra los efectos que la disputa tuvo en la vida cotidiana de sus semejantes. La "humanidad" de los indios pierde terreno cada día que pasa bajo la dominación española, una dominación que progresivamente los va considerando como simples cuerpos, sin derechos humanos ni "espíritu". La mirada de Poma sobre este paisaje de sufrimientos y de muerte no es exclusivamente moral, sino que ve destruidas a su alrededor ("todo en el suelo") (folio 1094), con la desaparición de los cuerpos, y por tanto de una cultura, las viejas esperanzas que la nobleza india había tenido de superponer el nuevo credo sobre el viejo cosmos. El objetivo siguiente de Poma es demostrar que, puesto que un gobierno justo y moral es la única justificación de la existencia del estado y del ejercicio del poder, éste no puede ser monopolizado de ningún modo por los cristianos (folio 948). Por el contrario, la historia-en el Viejo y en el Nuevo Mundo-le permitirá probar que los gobernantes paganos habían sido justos y amados por sus súbditos en mayor medida que muchos gobernantes que pretendían gobernar en el nombre del Rey español cristiano. En efecto, si se le preguntara su franca opinión, tendría que decir que encuentra a los Incas

30 Tanto esta crisis como las numerosas soluciones que se le dieron han sido recientemente discutidas en Lafaye, op. cit., pp. 30-50. 
incomparables: "No he hallado ninguno que haya sido de tan gran magestad" (folio 948).

Aunque una gran parte del libro está dedicada al recuerdo del sistema político social y económico Inca-sistema ejemplar a criterio suyo-Poma proclama que las bases del sistema fueron delineadas en tiempos de los Yarovilcas. En una constante oscilación de sentimientos exhibe tanto profundo desdén como admiración por los Incas. Como indio, toma partido con ellos como ejemplo de lo que los indios son capaces de realizar. Procede luego a probar que eran gobernantes justos a pesar de ser paganos y aun cuando habían conquistado y dominado a sus fuertes antepasados.

En otra de sus sabias especulaciones, imagina que Cristo nació el mismo año que Julio César estaba en Roma y Sinchi Roca en Cuzco, los dos centros cosmológicos o ciudades santas de estos imperios en conflicto. Aquí la intención de su argumento apunta al problema de la expansión territorial justa. Conquista e Imperio hallaron su justificación, y aún ahora la hallan, en su misión civilizadora (en nuestros tiempos llamada desarrollo). Para Huamán el Imperio Romano no fué una fuerza civilizadora mayor de la que había sido el Imperio Inca, y ninguno de estos Imperios eran menos virtuoso que el Imperio Español Cristiano. Como si no fuera suficiente, Poma prosigue recordándonos que los españoles habían vivido largo tiempo bajo el dominio del Imperio Romano y que nadie los culpaba por su previa sumisión a un gobierno pagano (folio 910).Fue sólo más tarde que se convirtieron al cristianismo, cuando el Apóstol Santiago les llevó la palabra. ${ }^{31}$ Así que, en cierto modo, los españoles son también conversos, ya que no nacieron cristianos ni son tampoco cristianos tan "antiguos" como pretendían ser (folio 934). La ciudad Santa de Roma podía presidir sobre los indios así como presidía sobre España. Por lo tanto no es inconcebible que los indios pudieran duplicar la conversión a la fe de los españoles y convertirse ellos mismos en los grandes defensores de la fe, en santos, teólogos, artistas religiosos, en todo lo que el ser humano es capaz de realizar (1102). Prueba de ello puede encontrarse en la vida de santidad de su medio hermano Martín de Ayala o en libros tan piadosos como la Primer Nueva Crónica.

El atrevimiento del yarovilca no se detiene aquí. Un buen gobierno requiere una apropiada delegación de autoridad, no la mera aceptación

31 No contento con haber rebajado a los españoles al nivel de los paganos postula la idea, popular en la época entre algunos frailes, de que San Bartolomé había venido al Perú en tiempos de Sinchi Roca y había predicado la fe Cristiana que con el tiempo se había relajado pero explicaba las "coincidencias" entre las creencias cristianas y las nociones indias de un creador, los santos espíritus, la vida después de la muerte, el bien y el mal, etc. Fray Antonio de la Calancha (1539) fue el promotor más importante de este punto de vista. Véase Lafaye, op. cit., p. 46. 
verbal de una doctrina político-religiosa. Cristo mismo dió el primer y mejor ejemplo al delegar su autoridad en San Pedro, que luego el apóstol delegó en los Papas/Roma. En este punto de su argumento, Huamán Poma invoca un orden pontificio del mundo al embarcarse en la más tediosa y oscura recitación de nombres y fechas de los Papas en la que intercala la línea de descendencia Inca. En parte entendemos esto si tenemos en cuenta su empresa niveladora. En el flujo del tiempo cristianopontificio ha habido muchos linajes de gobernantes: españoles, ingleses, incas, etc. Poma toca la raíz del problema cuando gentilmente le recuerda al Rey de España que su autoridad solamente se apoya en la doctrina del poder divino. Cristo dejó a Pedro, Pedro a los Papas, esto en cuanto a la extensión temporal diacrónica. En la extensión espacial sincrónica, los papas autorizan a los reyes, los reyes a los virreyes, y así ad infinitum. Un yarovilca noble puede ser el delegado del Rey y también el puente para la creación de un futuro estado indio separado.

La posición del rey ha salido indemne una vez más, aunque la administración de la justicia que de él emana es seriamente atacada. Lo que se cuestiona no es el derecho de España a tener un imperio en el Nuevo Mundo sino, más bien, quiénes deberían gobernar en nombre del rey-papaCristo. Habiendo demostrado previamente la incompetencia burocrática y la ineptitud moral de los españoles, Poma sólo puede ver otra elección lógica: los indios mismos. Ellos se habían manejado muy bien sin el beneficio de la Cristiandad y por lo tanto sólo podía esperarse que lo hicieran aún mejor con el legado de la nueva luz.

La defensa lógica, entonces, de un reino autónomo indio, parecía haber terminado. Los indios eran seres humanos recientemente introducidos a la Cristiandad, y, sobre todo, eran históricos y no naturales. Tenían su lugar en el tiempo, lo que los hacía merecedores de continuar existiendo en el flujo del Tiempo Cristiano / Histórico.

Desafortunadamente para Huamán Poma, faltaba aún resolver el problema constituido por el mayor enemigo natural de su labor ideológica: el mestizo. La descendencia que resultó de la unión "natural" o violación que la conquista produjo es el mayor obstáculo para los planes de Poma. En ninguna de las 1000 páginas hace Poma el menor esfuerzo por disimular su odio por el mestizo. No elabora una crítica moral del mestizo como hace con los españoles. Lo que informa sus acusaciones de pereza, falta de fijación, sensualidad y arrogancia es frecuentemente simple repulsión física. Solamente los zambos (negro e indio) son merecedores de igual odio y repugnancia. Sólo pensar en esta gente hunde a Poma en intolerable estado de enajenación. La pureza de la sangre y de la descendencia obran en la conciencia de Poma como categorías enceguece- 
doras, de tal manera que este abierto disgusto por el zambo, el mestizo y el mulato, se convierten en inesperada piedad y compasión por el esclavo negro, cuando dice que él es "humano también". Si bien conoce el problema de la pureza de sangre en relación a los judíos de España, Huamán piensa que los judíos son esencialmente españoles o, como se diría hoy, "caucásicos": "Considera que la nación española fue Judía aunque tuviera otra ley. $\mathrm{Y}$ tuvieron letra y traje, hábito y rostro y barbas. Conocieron muy de veras a Dios y tuvieron ley de Moisés y mandamiento, lo cual no tuvieron los Indios" (folio 937; ver también 915).

A juicio de Poma, el poder corrosivo, social y legal del mestizaje sobre la cultura indígena es crucial y abrumador. La imagen del mestizo toca un punto débil en todos los niveles físicos y morales de la conciencia de Poma. En lo más profundo, mestizaje significa que las mujeres indígenas darán a luz hijos cuyos seres físicos no perpetúan el ser material de los hombres de su misma etnicidad (folio 1105). Los hombres serán entonces condenados a la esterilidad. Poma cuenta muchos casos en que un hombre ha regresado de la mita (tributo de trabajo forzoso) para encontrar su casa llena de niños mestizos. Este hombre abandona su hogar, su villa, su mundo, para no dar salida a su disgusto, miedo y alienación matando a los hijos del Conquistador en su mujer ("por no matarlos") (ver también folio 1109). El amor narcisista del padre por su hijo, el amor egocéntrico del grupo étnico hacia sí mismo es negado por el mestizaje. La amenaza a la continuación personal, a la diferenciación misma, el miedo a la extinción racial, es más de lo que Huamán Poma y sus congéneres indios pueden soportar (folio 981).

A todo esto debería agregarse que el propio padre de Huamán Poma tuvo que hacer frente al mismo trauma. El "querido" medio hermano de Poma, Martín de Ayala, era, según nos cuenta, un mestizo. La especulación psicológica nos dirá que el "regalo", la violación, la seducción o la participación voluntaria de su propia madre en el nacimiento de este mestizo podrían constituir los fundamentos de esta repulsión física. Aún más, en una extraña nota personal, confía en el lector y confiesa: "mira cristiano, a mi todo se me ha hecho, hasta quererme quitar mi mujer un fraile mercedario. . . pretenden que fueran los indios bobos, asnos, para acabar de quitarle cuanto tiene, hacienda, mujer, hija" (folio 916);

Mestizaje significa también; en líneas generales, la pérdida por el grupo del control sobre el sistema reproductivo y de parentesco de la sociedad india. Huamán Poma sabe que ninguna ley de protección de los indios puede tener el menor efecto sobre la insoluble destrucción causada por el mestizaje (folio 1109 a 1118). Por los datos que presenta podría deducirse que las mujeres no comparten su repulsión por la noción de relaciones 
sexuales y culturales. ${ }^{32}$ (folio 1109). Algunas, las buenas a los ojos de Poma, se sentían tan avergonzadas cuando un religioso o corregidor había violado a todas en la villa, que ellas también huían y no volvía a saberse nada de ellas. Otras, sin embargo, no se horrorizaban tanto ante la idea de convertirse en la concubina de un español o de un negro y de tener hijos de ellos (folio 966). Huamán comenta: "y se acaban los indios por no tener mujeres y porque todas las mujeres se van detrás de los españoles" (folio 1018). Preocupado por el hecho de que esta nueva libertad en las relaciones ha afectado a los indios porque "ha desatado tanta lujuria entre los indios" (folio 888), y también preocupado por la despoblación de los pueblos indios, Huamán Poma insulta a las mujeres que se van con los españoles a las ciudades: "Las mujeres salen, se ausentan, salen de noche, se hacen bellacas, putas" (folio 880). Para él todas estas mujeres son traidoras y prostitutas (folio 1118). No puede ver otra motivación. Sin embargo, cuando describe la vida de la mujer ideal en tiempos pre-hispánicos, páginas después, parecería que muchas de ellas vieron en las ciudades españolas un refugio de la vida de infinito trabajo y sumisión a la autoridad masculina en la casa, en el campo y en toda otra esfera de la vida.

El trabajo es otro de los argumentos que Poma sostiene en contra de los mestizos. La indignación de Poma arde con furia implacable cuando los españoles se salen con la suya y no pagan a los indios por su trabajo. Pero el hecho de que el mestizo no esté obligado por la mita (nueve meses de trabajo impago para los señores y tres para ellos mismos) es para Poma el equivalente de un mundo al revés, o del infierno mismo. Si el mestizo no tiene obligaciones de trabajo, debería ser echado de las poblaciones indias. Que se unan al mundo de los españoles, con sus mulatos y zambos. $O$ mejor aún, que se los deporte a Chile, se los arroje al mar, pero que se los mantenga fuera de la vista de Poma, pues, como el marido engañado del teatro español, tiene deseos de matarlos él mismo.

El entrecruzamiento de razas no ocurre solamente fuera del matrimonio. Implica también el pecado de un sacerdote contra Dios y la sociedad, el

32 Aparte de que la violación de las mujeres indias era un hecho común, los españoles frecuentemente engendraban hijos en las mujeres que recibían como obsequio de los caciques indios que deseaban consolidar alianzas. Muchos soldados españoles se casaron con mujeres indias de linaje en función del sistema del rey consistente en asignar tierras indias a los españoles tan legalmente como fuera posible. Muchas mujeres indias que por el tributo de trabajo debían entrar al servicio de sacerdotes españoles etc., en sus casas, terminaron convirtiéndose en sus concubinas. Es también posible que las mujeres indias tuvieran la esperanza de que al tener hijos de los nuevos señores podrían salvar a sus hijos de la servidumbre y hacerlos más aceptables a la nueva sociedad, nueva sociedad que rápidamente se volvió racista. Véase Magnus Mörner, Race Mixture in the History of Latin America (Boston: Little, Brown and Company, 1967) 
robo de la virginidad y de la decencia de las mujeres indias (folio 971), produce el maldito y rebelde mestizo (folio 965), pero, sobre todo, debilita la fuerza de trabajo de las comunidades indias porque las mujeres se van y sus hijos no están sujetos a los sistemas de trabajo indígenas ni al tributo. El mestizo es una plaga casi tan perniciosa como el español mismo. ${ }^{33}$

Y peor aún, el daño recae sobre el rey mismo, porque sin indios, esto es, sin una fuerza de trabajo capacitada,

...se ha de perder la tierra porque ellos (españoles y mestizos) han causado gran daño y pleitos y perdiciones. Se perderá la tierra y quedará solitario y despoblado el reino y quedará muy pobre el rey por causa del dicho corregidor y demás españoles que roban a los indios sus haciendas, casa, sementeras, pastos, y sus mujeres, por asi casadas y doncellas, todas paren ya mestizos y cholos, hay clérigo que tiene ya veinte hijos y no hay remedio. (folio 446).

Un estado indio, en consecuencia, estaría dedicado a los tres fines que satisfacería los más altos intereses ideológicos y económicos del rey: la producción de súbditos cristianos leales y la producción de bienes destinados a satisfacer las necesidades de sobrevivencia de la fuerza de trabajo y de un excedente para las necesidades del estado. A pesar del argumento de Las Casas en favor de los derechos a la herencia de los mestizos, Poma ha logrado dejar bien claro que entre todos los súbditos del rey los únicos adecuados y capaces de realizar un "buen gobierno" son los indios mismos. Los mestizos serían los menos capacitados, pues como grupo no tienen ni historia ni cosmos que les sirva de modelo.

La intención final de Primer Nueva Crónica y Buen Gobierno se nos presenta al preguntarnos, como todo lector de la obra de Poma debe estar ahora preguntándose, cuáles serían los indios capaces de cumplir las promesas hechas al Rey. Si el proyecto del estado indio futuro tiene su modelo en el pasado, la nobleza india sobreviviente e históricamente responsable sería para Poma y para su fiel lector la respuesta inevitable. Especialmente los ancianos, pues ellos, además de recordar, representan una serie de negaciones básicas para la administración de un buen gobierno. ${ }^{34}$ Los ancianos no albergan ya deseos de placer personal o ambiciones de poder, no sufren la lujuria propia de hombres más jóvenes,

33 Irónicamente los altos funcionarios del rey tampoco consideraban al mestizo de utilidad alguna. Se lo consideraba pendenciero, rebelde, educado a medias, pretencioso, pero sobre todo de rápida propagación. Las cartas al rey abundaban en predicciones de rebeliones inminentes y en recomendaciones de que los españoles, mestizos y negros fueran deportados. Véase James Lockhart, "Letter and Peoples to Spain" (en Slavin, op. cit., pp. 783-796).

34 La tesis de Alfred Métraux de que los Incas "combinaban la forma más absoluta de despotismo con la mayor tolerancia hacia el orden social y político de los pueblos que subyugaban" podría también describir el proyecto para el futuro de Poma. Véase "The Inca Empire: Despotism or Socialism", (en Hanke, op. cit., p. 81). 
no codician un exceso de bienes materiales (en una sociedad sin propiedad privada no hay problemas de herencia), y no actúan movidos por ambición política para alcanzar honores y puestos más allá del presente. Los honores del mundo y la gloria del poder no son ya una tentación para los que están tan cerca del reino de Dios. Lo breve del tiempo que les queda por vivir, la proximidad de la muerte, los compele a un comportamiento ético. ¡Dios nos libre de las locuras y de los deseos experimentales de la juventud!

El inminente perfil "conservador" del futuro que Poma propone, sólo ha comenzado a mostrarse con su preferencia por una gerontología. Si propone un cambio total en el presente, es para terminar con el caos desatado en el Perú por los cambios que siguieron a la Conquista. Poma, al igual que otros soñadores de una sociedad perfecta, visualiza un estudio final de total estabilidad, notable por su pureza, coherencia, unidad y falta de contradicciones. La mezcla de categorías, la ambigüedad de las posiciones y las pluralidades actúan como desestabilizadores en su esquema del mundo. La singularidad, la separación, las diferenciaciones y la clasificación favorecen el orden, el conocimiento, el planeamiento y la predictibilidad. Cada objeto, cada tarea, cada acto y cada oficio, debe estar claramente diferenciado de los otros, para evitar la confusión y el error. Por lo tanto, habría hecho vestir a la gente con colores y ornamentos diferentes que señalaran, sin dejar lugar a dudas, su ocupación, clase, origen regional, responsabilidad y sexo. La organización total del estado estaría inscripta en el vestido de cada individuo. Entonces Poma podría complacerse en el deleite intelectual del orden: "Que bien se ve cada uno en su traje" (folio 797, ver también folio 1102).

La división de trabajo y de parentesco constituyen para Poma, en anticipación a la antropología moderna, los principios fundamentales de la organización humana. En el contrato social entre un miembro de la comunidad (me abstengo del término "individual" porque no creo que Poma lo interpretara en el mismo sentido que los europeos en los últimos doscientos años) y el estado, este último garantiza el derecho y la obligación universales de trabajar y de procrear. Para Poma todas las relaciones humanas están conformadas en relación al trabajo. El sexo, la capacidad física y las habilidades serían, como lo habían sido en el Imperio Inca, los criterios que se adoptarían para la asignación del tipo de trabajo. Los niños comienzan a trabajar tan pronto pueden subsistir un tiempo considerable lejos de sus madres. Antes de los cinco años, cuando comienzan a atrapar pequeños pájaros para arrancarles las plumas, también barren, traen leña y ayudan a cardar lana. No podría detenerme aquí en todos los detalles en que entra al planificar una división más amplia del trabajo, pues Poma encuentra verdadero deleite en describirlos. 
Diré simplemente que cada miembro de la comunidad trabaja - lo que para Poma es que él o ella existen socialmente - desde la edad de tres años hasta la muerte, en una interminable relación con el trabajo. Poma elogia a los Incas porque en sus tiempos aun a los nacidos con defectos congénitos se les daba trabajo y pareja. Frecuentemente el jorobado, el sordo y hasta el ciego llegaban a ser los mejores tejedores y alfareros de la comunidad y hasta del reino. También tenían hijos sanos. Bajo la dominación española, por el contrario, los ancianos y los enfermos asfixiaban las ciudades con sus cuerpos inútiles y sus manos extendidas tratando de consumir lo que no podían ya producir.

Su queja más amarga contra la administración española es la destrucción de la familia, que atribuye a la introducción de nuevos modos de producción. ${ }^{35}$ Poma no puede separar el confort emocional, el sentido de dignidad personal y el "amor", así como todos los otros valores "espirituales" por los que la familia es idealizada, de su visión de la familia como la unidad básica de procreación y producción. ${ }^{36}$

Para él la familia trabaja en primer término para satisfacer sus necesidades y por tal razón se les permite poseer unos pocos bienes de

35 En el esfuerzo de Poma por comparar la decadencia del presente Indio producida por el impacto de la cultura cristiana, con la estabilidad pasada y futura, se advierte un número sorprendente de coincidencias con las razones que los Indios de Nueva España daban para su propia decadencia aproximadamente en la misma época. La corona española había ordenado un cuestionario cosmográfico que se llevaría a cabo con el fin de descubrir la razón por la que los indios disfrutaban de mayor longevidad antes de la llegada de los españoles. La intención de las respuestas en general, al igual que los argumentos de Poma, confirman la superioridad de la cultura India. Austeridad en el vestir, comida, vivienda y sexo son citados como las causas de una mejor salud. Mejores curanderos, comida mensual, abstinencia sexual y sexo en la vejez eran considerados en México como las causantes de mejor salud y más larga vida. Otro punto de coincidencia es el trabajo. Mientras que en Nueva España la opinión estaba dividida en cuanto a si los indios trabajaban más o menos bajo el dominio español que bajo el azteca, en Poma uno encuentra una posición monolítica al denunciar el exceso de trabajo del sistema de la mita y de la encomienda. Esta denuncia está además acompañada de una expresión de pesar. Muchos indios desplazados se hallan recorriendo aldeas y villas holgazaneando en tambos y bares. Incapaces de encontrar trabajo, terminan su vida tristemente, solos y antes de lo que podría esperarse. Finalmente, George Kubler escribe que "en la vida colonial, cuando se imponía a los indios trabajo físico sin el adorno ceremonial ellos se convirtieron en desocupados psicológicamente, por así decirlo" (Veáse L.W. Hanke, op. cit., p. 182). En ambos casos la ausencia de orden y de pautas vitales es puesta de relieve y atribuida al caos que los españoles habían instituido.

36 El que Poma tuviera o no algún conocimiento de La República de Platón puede ser de interés para nosotros sólo con propósitos comparativos y no de filiación intelectual. Como he dicho anteriormente, Poma está usando el pasado andino como su modelo del futuro y me atrevo a decir que si él se enteró de las numerosas ideas utópicas que circulaban en la época, muchas de las cuales tenían el Nuevo Mundo como inspiración, tiene seguramente que haberse sentido regocijado y confirmado en su creencia de la posibilidad del "buen gobierno". El hecho de que Platón quisiera terminar con la familia porque sentía que el estado podría hacer una mejor labor de adoctrinamiento de los ideales de la república es de poca relevancia en cuanto a nuestro juicio sobre el proyecto de Poma. 
propiedad "privada": utensilios del hogar, animales domésticos, etc. El excedente producido por el trabajo fuera de la casa, y a veces dentro de ella, sea éste de tejidos o huevos, sostiene al estado. En una sociedad de economía no monetaria, los oficiales del estado son remunerados en bienes destinados al consumo y no a la acumulación, menos aún al despilfarro del banquete $o$ a las vestimentas ornamentadas de los españoles. El papel del estado sería mínimo y por lo tanto no demandaría grandes gastos. No existirían los "comenderos (que) gastan largamente como no les cuesta su trabajo, ni sudor, sino que pide a los pobres indios" (folio 559). Y al Rey se le daría su tributo en mercancía y también en trabajo-plata, coca, ganado y oro-para que disponga de ello como le plazca. La conversión de las mercancías a usos y valores ajenos a la economía indígena al integrárselos a la economía mercantil del imperio español no era de su incumbencia, siempre que los españoles mantuvieran el perverso sistema para uso exclusivo de ellos mismos.

En este mundo de trabajo, el estado es comparable a una verruga en la suave epidermis de un cuerpo gigantesco de trabajadores. El estado sería una presencia invisible encargada de vigilar el funcionamiento de la sociedad en un estado de equilibrio estable. El mayor cambio que la conciencia de Poma puede tolerar es una lenta adaptación a los fracasos inesperados de la máquina perfecta. Para él no existe nada más aborrecible-exceptuando los mestizos-que la noción de cambio rápido o experimentaciones o de ascenso social en la vida a expensas del trabajo de los demás. ${ }^{37}$ En una de las muchas escenas que describe, ridiculiza a la familia española que, en la pobreza, imagina para su descendencia riquezas en el Nuevo Mundo.

A fin de mantener tranquilos a los mercedarios y otros religiosos y para convertir en realidad un estado indígena independiente, la segunda etapa de su utopía tendrá que realizarse por escrito. El Rey debe decretar su existencia y el retorno al pasado comenzará con la restitución de la tierra a sus dueños originales. Poma escribe: "Es muy justo que se vuelva y restituya las dichas tierras y corrales y pastos que se vendieron en nombre de su majestad, porque de bajo de conciencia no se le puede quitarsela a los naturales, legítimos proprietarios de las tierras... Después que se les vuelva los indios e indias les valdrá muy mucho a su majestad" (folio 536). Poma no advierte la red de complicaciones insolubles que surgirían al producirse el cambio de un sistema de propiedad privada al sistema previo de propiedad comunal, especialmente después de la dispersión inicial de los

$37 \mathrm{Si}$ bien tanto la sociedad Inca como la española estaban clara y firmemente jerárquicamente orientadas y Poma desprecia al soldado español que quiere ser tratado como si fuera un señor, sus observaciones aquí se centran en el problema de la propiedad del trabajo. 
indios ocasionada por la guerra y por la encomienda. De modo que la transferencia de la tierra se haría de acuerdo a los derechos existentes en tiempos de su abuelo, Tupac Inca Yupanqui "y si fuere común sementera o pastos de los pueblos de quien fuere justo título desde abinicio y desde Topa Inca Yupanqui... y a los indios que no fueren herederos se los arriende y paguen un tanto al dicho dueño" (folio 536).

Por más atractivo o necesario que el estado indio independiente pudiera haberle parecido al Rey, la abrogación de los derechos de conquista era una carta políticamente imposible de jugar. La corona tenía suficientes problemas con el control de los viejos súbditos españoles en el Nuevo Mundo para correr el riesgo de proponer, aunque fuera solamente por escrito, la autonomía económica y política de los indios. Aun cuando Poma ofrecía la promesa de mayores excedentes para la Corona, además de mayor número y mejores almas cristianas, las fuerzas que conformaban el mundo colonial hispánico, frecuentemente en amplio desacuerdo con los deseos de la Corona, eran incontrolables por las vías del interés ideológico aislado. Lo que Poma hace en Primer Nueva Crónica, aparte de rescatar del olvido un legado cultural, es proponer convincentemente un estado étnico independiente dentro de los parámetros ideológicos (limitaciones) de la cultura dominante. Su mayor fracaso, no mayor que los de sus muchos contemporáneos que perseguían cambios similares, era creer que la historia podía ser cambiada por la petición de un príncipe ("que soy su príncipe y protector") (folio 981) a otro, sin tener en cuenta cuán absoluto el poder del otro podía parecer. Aunque Huamán Poma entendía que el funcionamiento de la sociedad era un proceso orgánico, no otorgaba al cambio político drástico un atributo similar. Podría escribirse un libro sobre las razones por las que su sueño fracasaría. En las últimas cien páginas de su manuscrito comienza a vislumbrar la imposibililidad de su sueño. Defiende a sus indios como el príncipe debe hacerlo con sus súbditos, aún cuando sus nuevos señores se nieguen a oir sus reclamos "y así escribo esta historia para que sea memoria y se ponga en el archivo de la justicia" (folio 981). Con esta oración comienza a dedicar su obra a un espacio aislado de la escritura, como si ésta misma fuera un espacio separado del resto del mundo. Y sin embargo cuando Huamán Poma formula su pregunta principal: ¿Cómo nosotros, una entidad étnica y cultural, lograremos sobrevivir?, está formulando la pregunta histórica crucial. Más adelante, cuando se refiere al exceso de trabajo y a la mezcla de razas como peligros principales para la realización de su proyecto de resistencia, nuevamente acierta al percibir que el momento que los indios del Perú estaban viviendo era desesperado. 
El análisis del proceso de despoblación de México, de Woodrow Wilson Borah, aclara, retrospectivamente, lo que Huamán Poma había advertido y trataba de expresar a fines del siglo dieciséis con respecto al Perú.

El agudo y continuado descenso de la población de los indios de México a partir de la Conquista hasta el comienzo del siglo XVIII debe ser considerado como uno de los factores más importantes en la historia de México. Si las poblaciones originales del centro de México hubieran soportado el impacto de la conquista con poca pérdida demográfica los conquistadores podrían haber tenido escasas oportunidades, excepto como administradores o cobradores de tributos. México sería hoy un área indígena de la cual, un estrato más alto blanco en el proceso de lograr la independencia de España y que se mantenía separado, como los británicos en la India, podría haber sido fácilmente expulsado. ${ }^{38}$

Resulta entonces que el sueño de Poma tenía sus raíces en la realidad y que podría haberse llevado a cabo-y esto era ya verdad en los tiempos en que escribía-si sus más graves temores (despoblación y mestizaje) no hubieran galopado al frente de sus esperanzas más queridas. 
